\title{
Technology Implementation Plan: Irradiation Testing and Qualification for Nuclear Thermal Propulsion Fuel
}

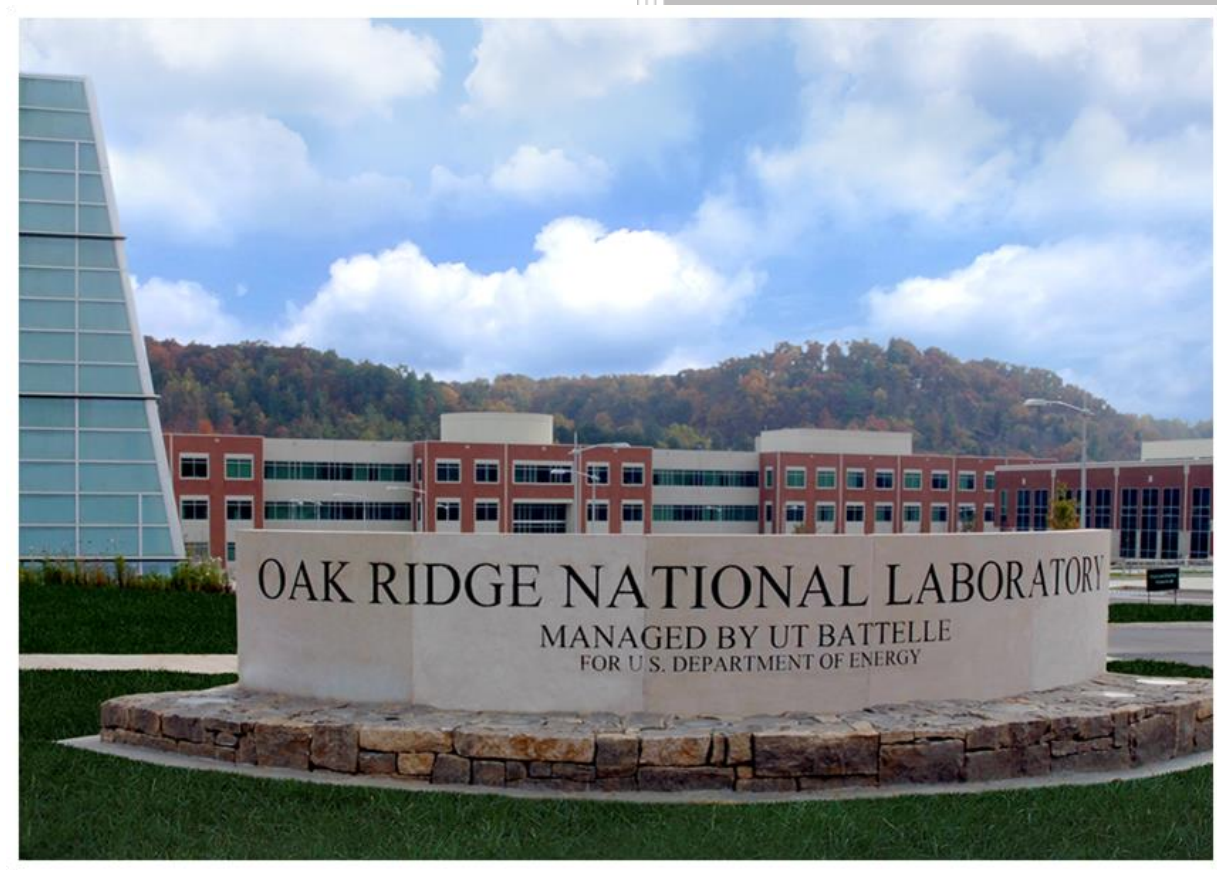

Approved for public release. Distribution is unlimited.
R. H. Howard

T. J. Harrison

J. D. Rader

September 2017 


\title{
DOCUMENT AVAILABILITY
}

Reports produced after January 1, 1996, are generally available free via US Department of Energy (DOE) SciTech Connect.

Website http://www.osti.gov/scitech/

Reports produced before January 1, 1996, may be purchased by members of the public from the following source:

\author{
National Technical Information Service \\ 5285 Port Royal Road \\ Springfield, VA 22161 \\ Telephone 703-605-6000 (1-800-553-6847) \\ TDD 703-487-4639 \\ Fax 703-605-6900 \\ E-mail info@ntis.gov \\ Website http://classic.ntis.gov/
}

Reports are available to DOE employees, DOE contractors, Energy Technology Data Exchange representatives, and International Nuclear Information System representatives from the following source:

Office of Scientific and Technical Information

PO Box 62

Oak Ridge, TN 37831

Telephone 865-576-8401

Fax 865-576-5728

E-mail reports@osti.gov

Website http://www.osti.gov/contact.html

This report was prepared as an account of work sponsored by an agency of the United States Government. Neither the United States Government nor any agency thereof, nor any of their employees, makes any warranty, express or implied, or assumes any legal liability or responsibility for the accuracy, completeness, or usefulness of any information, apparatus, product, or process disclosed, or represents that its use would not infringe privately owned rights. Reference herein to any specific commercial product, process, or service by trade name, trademark, manufacturer, or otherwise, does not necessarily constitute or imply its endorsement, recommendation, or favoring by the United States Government or any agency thereof. The views and opinions of authors expressed herein do not necessarily state or reflect those of the United States Government or any agency thereof. 
Reactor and Nuclear Systems Division

TECHNOLOGY IMPLEMENTATION PLAN:

IRRADIATION TESTING AND QUALIFICATION FOR NUCLEAR THERMAL PROPULSION FUEL

R. H. Howard

T. J. Harrison

J. D. Rader

Date Published: September 2017

Prepared by

OAK RIDGE NATIONAL LABORATORY

Oak Ridge, TN 37831-6283

managed by

UT-BATTELLE, LLC

for the

US DEPARTMENT OF ENERGY

under contract DE-AC05-00OR22725 



\section{CONTENTS}

Page

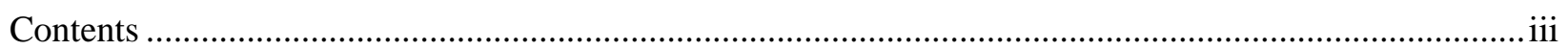

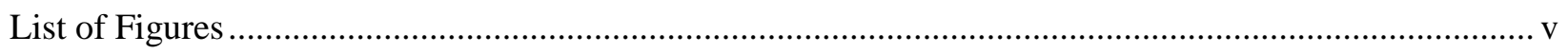

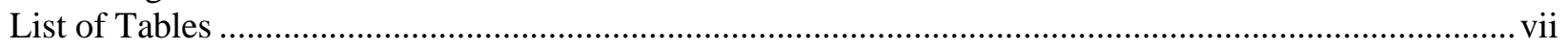

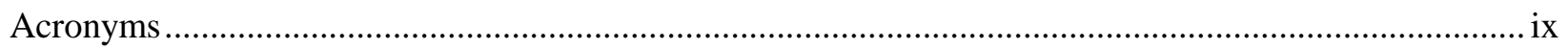

1. Introduction and Technology Overview …........................................................................... 1

$1.1 \quad$ Background of Nuclear Thermal Propulsion Technology ........................................................ 1

1.2 Overview of this Technology Implementation Plan ................................................... 2

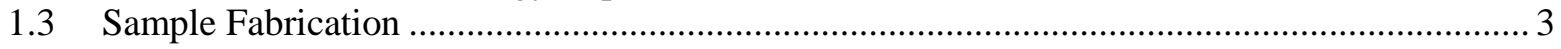

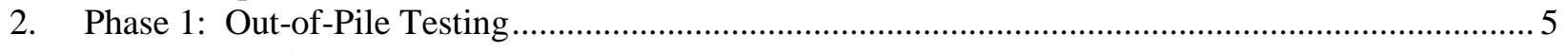

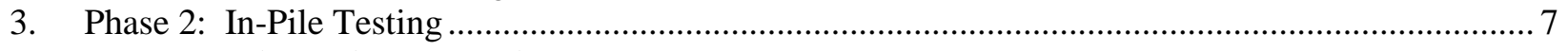

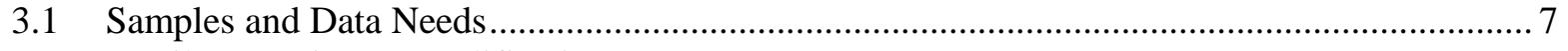

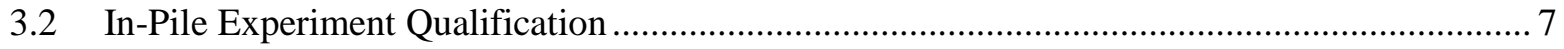

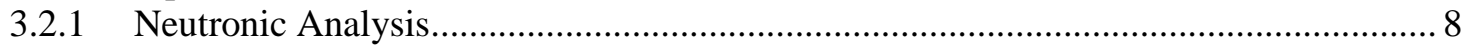

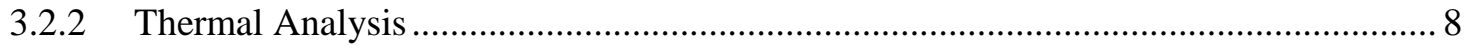

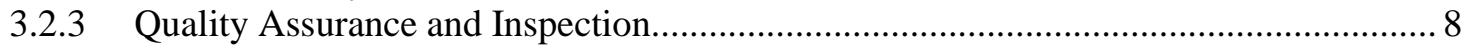

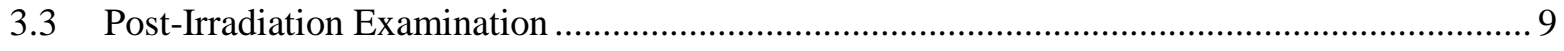

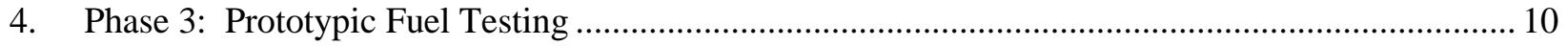

4.1 Qualification of a Prototypic Fuel Experiment ….................................................................. 10

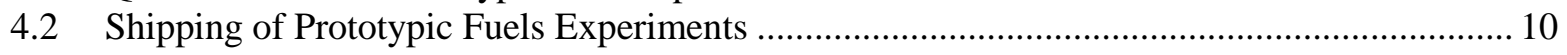

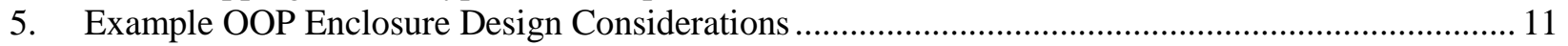

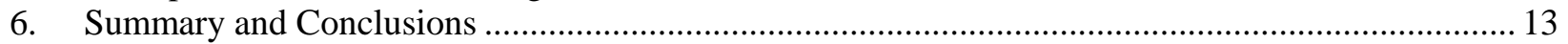

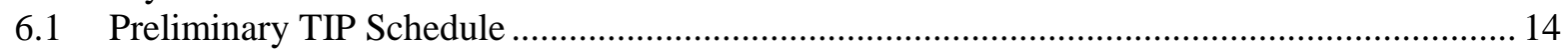

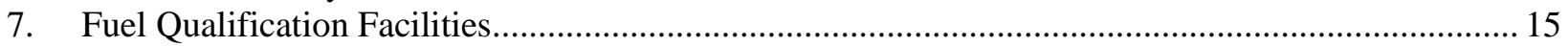

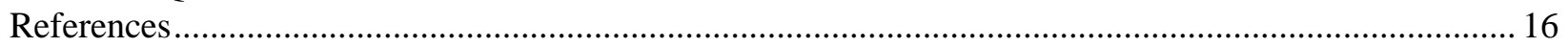




\section{LIST OF FIGURES}

Page

Figure 1-1. Flow chart of the technology implementation plan....................................................... 2

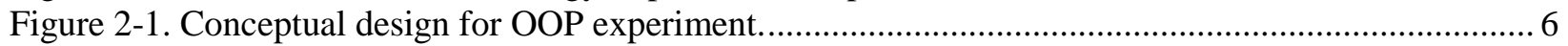

Figure 5-1. SIGRATHERM GFA thermal conductivity as a function of temperature (reproduced

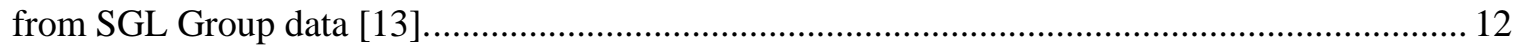

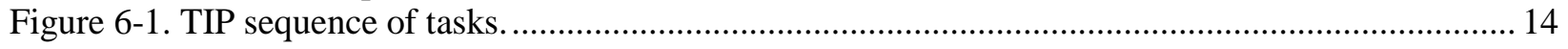




\section{LIST OF TABLES}

Page

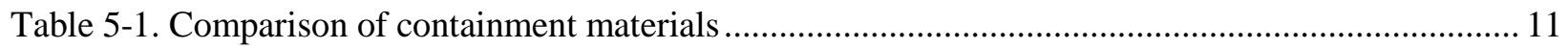

Table 6-1. Properties and parameters of interest to support NTP fuel qualification................................ 13

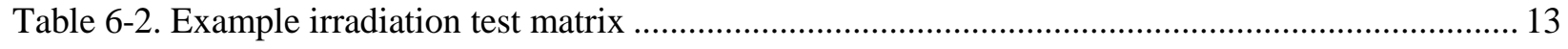




\section{ACRONYMS}

$\begin{array}{ll}\text { ASME } & \text { American Society of Mechanical Engineers } \\ \text { ATR } & \text { advanced text reactor } \\ \text { CF } & \text { ConFlat® } \\ \text { CFR } & \text { Code of Federal Regulations } \\ \text { CTE } & \text { coefficients of thermal expansion } \\ \text { DOE } & \text { US Department of Energy } \\ \text { HFIR } & \text { High Flux Isotope Reactor } \\ \text { IP } & \text { in-pile } \\ \text { NERVA } & \text { Nuclear Engine for Rocket Vehicle Application } \\ \text { NQA-1 } & \text { Nuclear Quality Assurance 1 } \\ \text { NRAD } & \text { Neutron Radiography Reactor } \\ \text { NRC } & \text { US Nuclear Regulatory Commission } \\ \text { NTP } & \text { nuclear thermal propulsion } \\ \text { NTR } & \text { nuclear thermal rocket } \\ \text { OOP } & \text { out-of-pile } \\ \text { ORNL } & \text { Oak Ridge National Laboratory } \\ \text { PIE } & \text { post-irradiation examination } \\ \text { QAP } & \text { quality assurance plan } \\ \text { SAR } & \text { safety analysis report } \\ \text { TEM } & \text { transmission electron microscopy } \\ \text { TIP } & \text { technology implementation plan } \\ \text { TSD } & \text { transportation safety document } \\ \text { TSR } & \text { technical safety review }\end{array}$




\section{INTRODUCTION AND TECHNOLOGY OVERVIEW}

This document is a notional technology implementation plan (TIP) for the development, testing, and qualification of a prototypic fuel element to support design and construction of a nuclear thermal propulsion (NTP) engine, specifically its pre-flight ground test. This TIP outlines a generic methodology for the progression from non-nuclear out-of-pile (OOP) testing through nuclear in-pile (IP) testing, at operational temperatures, flows, and specific powers, of an NTP fuel element in an existing test reactor. Subsequent post-irradiation examination (PIE) will occur in existing radiological facilities. Further, the methodology is intended to be nonspecific with respect to fuel types and irradiation or examination facilities.

The goals of OOP and IP testing are to provide confidence in the operational performance of fuel system concepts and provide data to program leadership for system optimization and fuel down-selection. The test methodology, parameters, collected data, and analytical results from OOP, IP, and PIE will be documented for reference by the NTP operator and the appropriate regulatory and oversight authorities. Final full-scale integrated testing would be performed separately by the reactor operator as part of the preflight ground test.

\subsection{BACKGROUND OF NUCLEAR THERMAL PROPULSION TECHNOLOGY}

NTP technology is designed to provide in-space vehicle propulsion by deriving thrust from a hydrogen working fluid that is heated by passing through a high-temperature nuclear reactor. This technology generates a very high, specific impulse ( $900 \mathrm{~s}$ ) which is estimated to be over twice that of contemporary chemical combustion rockets [1]. The increased efficiency allows for higher payload masses per launch and provides higher velocities to be reached during transit when compared to chemical rockets. Higher achievable velocities will shorten transit times which lower astronaut exposure to ionizing radiation from galactic cosmic rays and decrease the potential for experiencing a solar particle event [2].

Domestic research and development for NTP has roots in the Rover / Nuclear Engine for Rocket Vehicle Application (NERVA) program that was in operation from 1955 through 1972. During that time, multiple NTP engines were developed and tested to withstand multiple firing cycles at high temperatures $(>2400$ K) [3]. The Rover/NERVA program was discontinued in 1973, and most domestic research and development for a high-temperature NTP fuel system was halted. Over the next two and a half decades, smaller efforts to model and improve potential NTP fuel structures have been made, but no significant, concerted effort to revive this technology has come to fruition. However, in 2010, the US National Space Policy dictated that the United States would, "by 2025, begin crewed missions beyond the Moon, including sending humans to an asteroid. By the mid-2030s, send humans to orbit Mars and return them safely to Earth" [4]. To support this policy, efforts were resumed to qualify a propulsion system that uses nuclear fuel with a hydrogen working fluid in lieu of the less efficient chemical rocket system [1].

A major component of this work is to qualify the nuclear fuel system for use. As mentioned above, developments in processing, fuel fabrication, and testing were made in the 1960s and 1970s to bring this technology into a mature state sufficient for powered ground tests of NTP engines. Unfortunately, most of the equipment and key personnel have been lost to time, and much of this development must be reproduced. The Rover/NERVA program did leave a reasonable amount of technical data to aid current researchers in standing up a modern NTP fuel program to support future crewed missions to Mars. This information is being used to inform modern fuel fabrication processes, approaches to testing this material, and the content of this plan. 


\subsection{OVERVIEW OF THIS TECHNOLOGY IMPLEMENTATION PLAN}

A preliminary test plan that details NTP fuel qualification was completed in 2017. [5] This plan establishes five technical areas of focus: (1) fuel fabrication, (2) non-nuclear (i.e., surrogate) fuel testing, (3) irradiation testing, (4) PIE, and (5) safety testing. Multiple fuel forms, including graphite-based forms similar to the Rover/NERVA program, are being developed. This includes (U,Zr)C/graphite composite fuels and $\mathrm{UO}_{2} / \mathrm{W}$ ceramic/metallic ("cermet") fuels, among other fuel form concepts. All qualification context described in this document applies to all form concepts and will henceforth be referred to simply as fuel. This document applies to all NTP fuel forms, even those unknown, though the composite and cermet fuel forms are the likely options for near-term testing. Regardless of form, all testing and qualification relies on a robust fuel production system with the appropriate acceptance criteria and formal fabrication process of record.

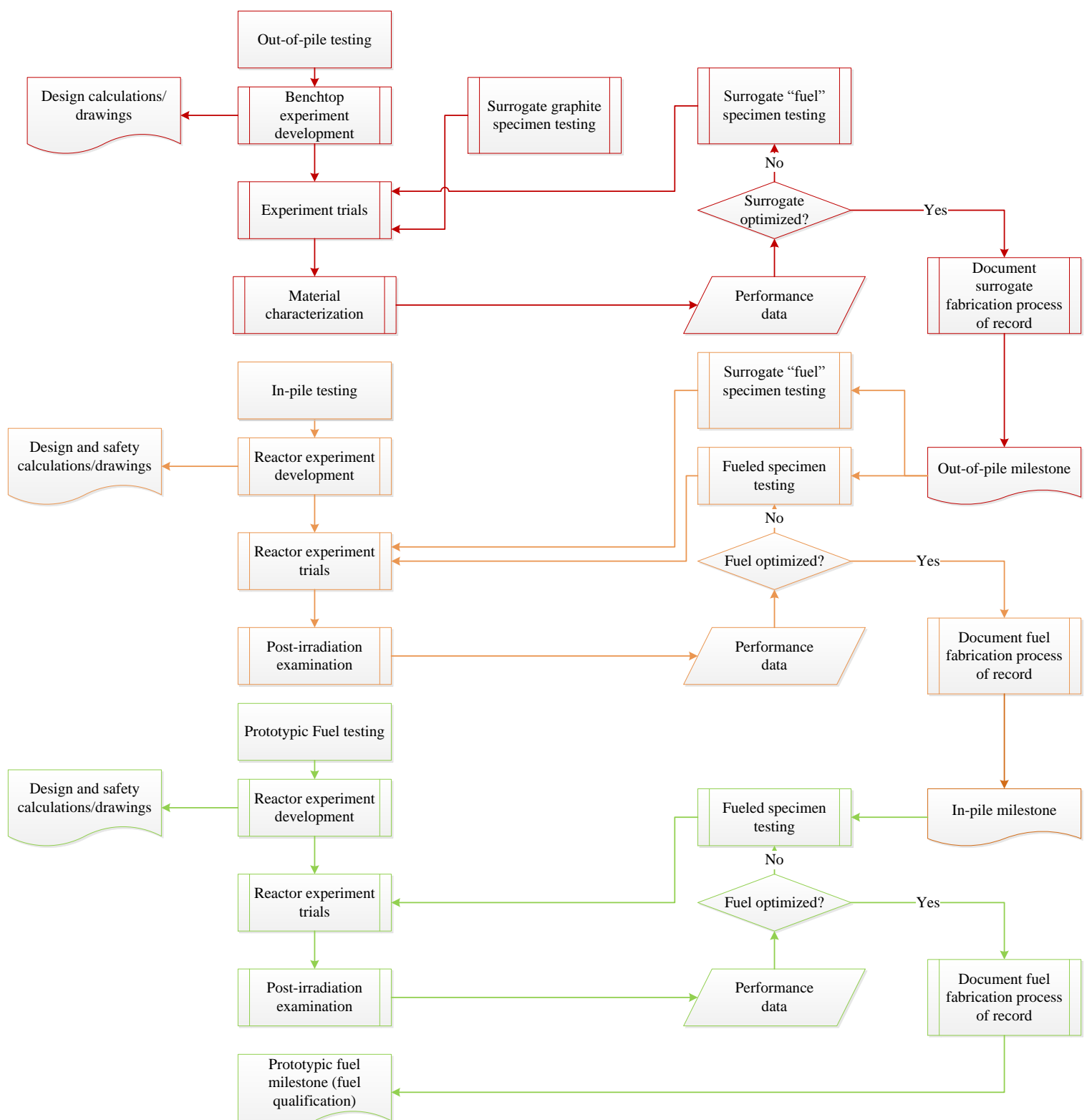

Figure 1-1. Flow chart of the technology implementation plan. 
In general, testing of small-scale surrogate and enriched fuel specimens will be conducted to expose the material to prototypic conditions and to glean performance data for prototypic geometries, with the additional goal of identifying limiting operating conditions and critical failure mechanisms to optimize fabrication parameters and inform fuel down-selection. Upon completion of the surrogate and fueled nonprototypic specimen testing and development, a series of full-scale fuel element irradiation experiments will be conducted. This effort will expose prototypic fuel geometries to the expected limiting case conditions (i.e., hydrogen atmosphere at elevated temperatures) to formally establish the final fuel geometries and production parameters. The prototypic geometry irradiation test matrix will be tailored to establish data for normal operation and limiting condition (i.e., safety/accident) scenarios. PIE will be conducted for each phase of irradiation testing. A high-level conceptual flow chart of the technology implementation plan can be seen in Figure 1-1.

For historical context, the initial fuel structures developed by the Rover/NERVA program were designed to withstand temperatures exceeding $2,400 \mathrm{~K}$ and remain intact after tens of firing cycles [3]. The current development program requires that fuel withstand temperatures between 2,550-2,900 K under similar duty cycles [1] [5]. Experiments will be developed to subject fuels to these conditions with the objective to provide data and performance information for optimization and potential down-selection of candidate materials. These first tests will not expose the surrogate and fueled specimens to the hydrogen working fluid, focusing solely on the thermal performance of the specimens. External electrical or fission energy sources and a controlled vacuum/inert gas atmosphere will provide the conditions required to reach operating conditions.

Initial fuel testing shall be initiated in two phases, as detailed below. A third phase to test prototypic geometries at normal and off-normal conditions is discussed in section 3 .

\section{- Out-of-pile (OOP) testing:}

- Perform thermophysical property measurement (e.g., coefficient of thermal expansion, thermal conductivity, and emissivity) with standard techniques and commercially available equipment

- Perform material characterization on samples to gain understanding of degradation of material properties (e.g., toughness, tensile strength, grain structure) as a function of thermal cycling

- Develop and characterize an experiment to electrically heat surrogate specimen materials to characteristic temperature

- In-pile testing (IP): extrapolate the OOP design for use in a research reactor, and irradiate surrogate and fueled samples

OOP testing will provide proof-of-principle performance characteristics of an electrically heated benchtop enclosure that encapsulates surrogate fuel material. The OOP enclosure shall be designed to mirror the IP capsule enclosure, where surrogate and fueled specimens will be heated through nuclear fission. This enclosure device will be exercised to ensure that accurate, reproducible conditions can be achieved, thereby providing confidence that the analogous IP experiment will perform adequately while relying mostly on limited instrumentation and virtually passive control. Upon OOP enclosure qualification, the IP experiments will then be loaded with surrogate specimens to compare performance data against benchmark OOP data. After the surrogate fuel performance is verified, the IP enclosure will be used for irradiated fueled specimens.

\subsection{SAMPLE FABRICATION}

To insert material into a research or commercial reactor, a researcher is generally required to maintain stringent control on material pedigree and material traceability during the fabrication process, provide 
nuclear performance data pertaining to heating rates and reactivity, and have some process of record for fabrication to verify that the material meets performance specifications. This information is documented in accordance with an approved quality assurance program such as the American Society of Mechanical Engineers (ASME) Nuclear Quality Assurance 1 (NQA-1) regulatory standard and is provided in a fabrication package for approval by the reactor operation entity. Quality assurance and inspection details are described section 3.2.3.

It is important to have the performance data described in the previous paragraph to perform the necessary irradiation capsule work. Performance and safety basis calculations must be approved before a capsule is inserted into a reactor user facility. These calculations will describe the capsule design through engineering drawings and constituent (i.e., supporting part) and sample material properties. The calculations will also demonstrate that the design remains intact when introduced to facility-specific offnormal conditions. The limits of test conditions should be detailed in the facility's safety analysis report (SAR). 


\section{PHASE 1: OUT-OF-PILE TESTING}

The first phase of the fuel irradiation effort generates a knowledge base for the performance of the fuel form at operational temperatures and propellant flow in OOP tests. The OOP tests follow a logic loop which will be repeated in subsequent phases: test, analyze, adapt. The OOP tests are expected to result in a fuel element material, geometry, and production method which all show adequate, if not totally optimized, performance in a simulated rocket environment.

The OOP experiment must balance the need to quickly generate applicable data with the ability to learn from failure. Therefore, the test environment must be controllable, especially with respect to temperature cycling, and it must also be instrumentable to capture the necessary performance information.

The experiment should provide three basic functions:

- Provide electrical heating (directly, through induction, etc.) to allow the specimen to achieve target temperatures. Preliminary scoping calculations were performed to estimate the heat load required to bring a graphite specimen up to target temperature $(\sim 2,800 \mathrm{~K})$ in a vacuum environment. This study showed that less than $1 \mathrm{~kW}$ of electrical power would be suitable for the task; comparable calculations can be performed for cermet or other fuel types. A consideration should be made to run the experiment in an inert gas (e.g., He or Ar) to characterize higher heat flux cases like those to be observed in fueled specimen IP tests or in propellant gas (i.e., H). By scaling the heat input to reflect nominal target power densities ( $>5 \mathrm{MW} / \mathrm{L})$, the demand is on the order of $8-10 \mathrm{~kW}$. Conversely, the enclosure must also have reliable cooling methods.

- Design flexibility to accept various direct and indirect instrumentation techniques. Validation and verification of experimental performance is crucial to the OOP testing mission. Conventional thermocouples will not survive such high operating temperatures, but they can be used for lower temperature shakedown testing. They can also be used to validate optical measurement techniques at lower temperatures, providing confidence in sample temperature measurements during normal operations.

- Provide and maintain a controlled vacuum or inert atmosphere. This aspect of the experiment is crucial to controlling heat transfer, and it is also necessary for protecting the experiment samples. Active gas evacuation, delivery, and monitoring systems should be considered to ensure that conditions within the experiment remain controlled. These elements would also provide the ability to quench the specimen in an inert gas to simulate rapid cooling transients. The use of getter materials may also be required to remove residual oxygen in the enclosure. Pure titanium foil is a likely selection for a vacuum/inert atmosphere based on its relatively high getter capacity $\left(4.4 \mathrm{~Pa}-\mathrm{L} / \mathrm{mg}\right.$ for $\mathrm{O}_{2}$ at $\left.20{ }^{\circ} \mathrm{C}\right)$. However, alternate material such as cerium may be selected if getters are used in a hydrogen atmosphere, since titanium has a getter hydrogen capacity of roughly 8 times that of oxygen [6]. 
Figure 2-1 shows a notional concept of the OOP experiment.

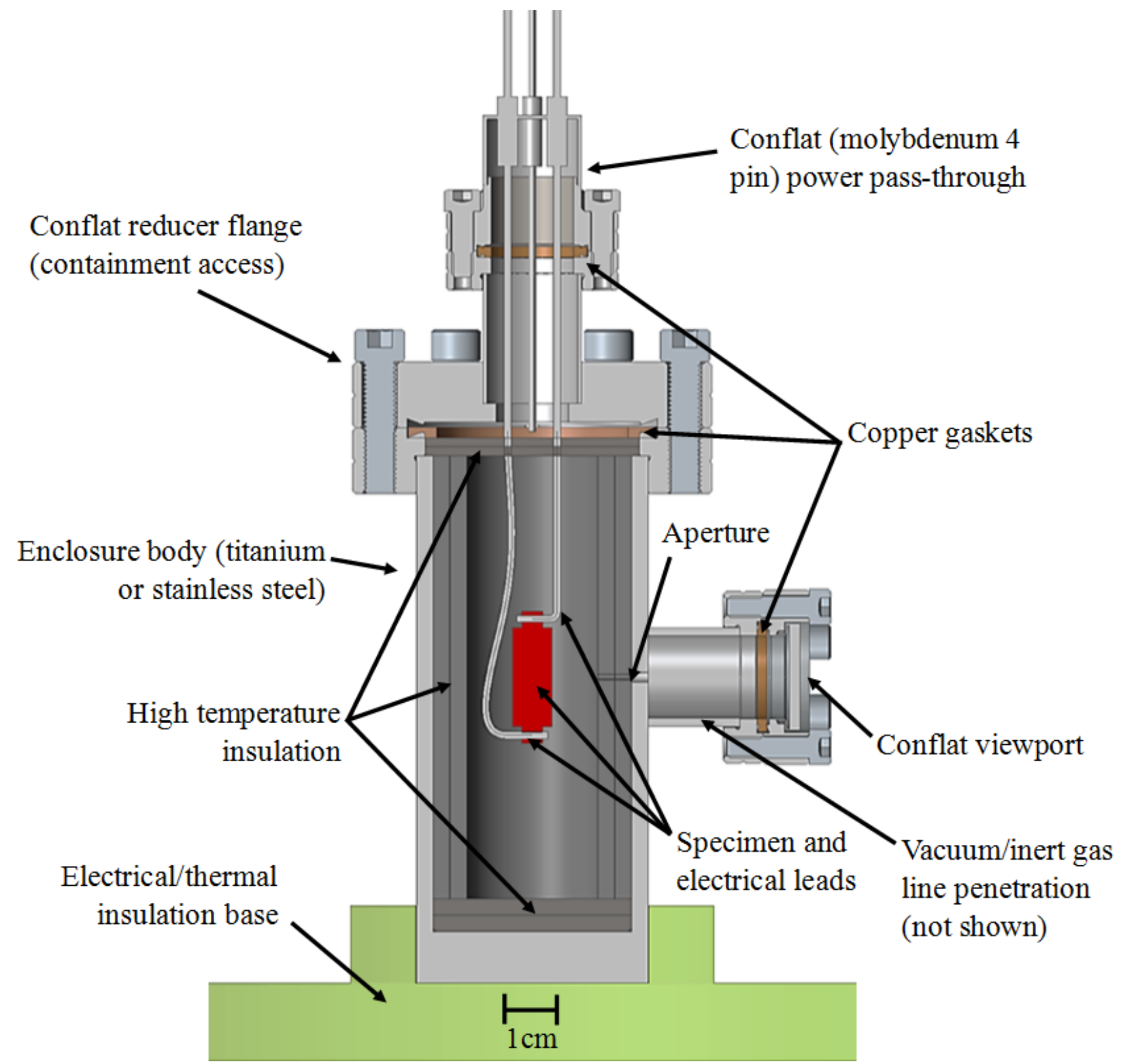

Figure 2-1. Conceptual design for OOP experiment.

While the specimen is somewhat generalized in the figure, the notional planned geometries are $3 \mathrm{~mm}$ cylinders that will be sectioned or ground to various shapes. The workhorse specimen for early tests will be the $3 \mathrm{~mm}$ transmission electron microscopy (TEM) disk, which will provide microstructure evolution data. The $3 \mathrm{~mm}$ cylinder can be subsequently ground into round tensile specimens and tested for fatigue and tensile fatigue data. The experiment will be designed to accommodate other specimen geometries as needed. These specimens will also be compatible with the subsequent IP experiments. 


\section{PHASE 2: IN-PILE TESTING}

This phase of the technology implementation plan will produce reactor-ready experiments to qualify fueled sample fabrication methods for use in later testing under prototypic conditions and geometries. This work builds on the information and technology learned from the OOP testing described above. Sample testing methodologies will be produced and refined to ensure that irradiation samples can be processed and analyzed for comparison with the OOP benchmark data. Reactor and PIE site selection will be based on the types of irradiation testing required to produce this data. The irradiation profile, including power and temperature ramping and neutron spectrum, will be considered when choosing irradiation facilities.

\subsection{SAMPLES AND DATA NEEDS}

Reference samples (unfueled and fueled) will be provided for IP testing. Initial experiments should be unfueled and should replicate OOP conditions. With surrogate materials, it is possibly that prototypic temperatures may not be reached due to the potential reduction in power densities. Under these circumstances, lower power/temperature OOP reference cases should be used, or the specimens should have supplemental electrical heating to help them achieve prototypic temperatures. PIE on surrogate materials will produce data to verify that the irradiation experiment enclosure performs sufficiently. Once surrogate IP enclosure experiments are completed, fueled experiments will ensue. Aside from the particular material/thermophysical properties data of interest identified in section 1.2, IP experiments will also gather data to aid in understanding the fuel's nuclear performance. For example, these data may include fission product retention and release under the necessary range of temperatures and burnups of interest. This secondary effect is required to understand fuel microstructural changes and to provide data to predict these changes as a function of thermal cycling and burnup.

Fuel irradiation testing allows for the use of capsule testing in current facilities to efficiently complete screening of fabrication process parameters and establish fuel behavior under irradiation. Experiments should be designed to produce expected prototypic conditions for fuel elements (temperature and power density, burnup conditions) to produce data to quantify fuel properties such fission product behavior and retention, structural behavior, and thermophysical property evolution. Historic tests from the Rover/NERVA program indicated that mid-band regions of the fuel were most susceptible to mass loss due to high power densities, accumulated thermal stresses, and coating imperfections, in spite of lower operating temperatures [7] [8]. The proposed IP test matrix should verify that the fuel is capable of holding up under benchmark temperatures and conditions established through OOP screening tests. However, characterization of fuel system embrittlement in the mid-band region of the core is important for quantifying the role of irradiation versus thermal degradation [5].

\subsection{IN-PILE EXPERIMENT QUALIFICATION}

The major effort in implementing an IP experiment is qualifying the experiment design for reactor use. This process is much more rigorous than in OOP experiments because the IP design must not only perform according to researcher requirements, but it also must not perform in a manner that impacts reactor operations or violates reactor safety requirements. Generally, research reactors are licensed to operate and comply with regulator-approved documents and procedures, the most important of which are the SAR and technical safety review (TSR) documents. These documents specify guidance and limitations for reactor components and experiments, and they provide information on the off-normal and accident scenarios that all reactor components and experiments must consider. An analysis package will be completed to demonstrate capsule performance for the various normal, off-normal, and safety basis scenarios for selected user facilities. This includes a reactor performance design basis and safety basis analysis for neutronic and thermal performance. Considerations for onsite shipping at a user facility, as 
well as for offsite shipping, are an important consideration during the qualification process. However, due to the expectation of relatively low levels of activated radioactivity associated with these IP tests, it is expected that shipping qualification will be routine. This topic is described in further detail in Section 4.2.

\subsubsection{Neutronic Analysis}

Neutronic analysis of the IP configuration in some lattice physics or stochastic code will be performed to calculate normal operation heat generation rates, reactivity penalties, fission densities, and activation of experimental components. This information is used to support thermal analysis and PIE efforts. A second set of calculations will be produced to establish the bounding nuclear performance data required to define a reactor safety basis. Since the bounding calculations will be used to qualify the experiment for use in the designated user facility (reactor), this work will be performed in accordance with the protocols set forth by the reactor's SAR/TSR.

To perform these analyses, designers and engineers require a reasonable model and source term for the reactor in which the experiment will be operated. This information will provide performance data for experiment-specific locations, including proximity to fuel, control rods/plates, and other experiments. All of these data have the potential to impact the neutronic performance of the experiment.

\subsubsection{Thermal Analysis}

Similar to the neutronic and OOP thermal analyses, the initial phase of the thermal analysis is to establish a design basis that complies with researcher's requirements. The design basis is usually defined through an iterative process to balance total heat generations and heat losses through conduction, radiation, and convection to achieve a desired specimen temperature. The process is iterative because neutronic analysis is sensitive to thermal performance and vice versa. For example, if the capsule is designed to operate in a hard vacuum in which heat transfer is generally limited to conduction and radiation, then the introduction of fission gas in the environment would produce some limited conduction/convection through that medium. Moreover, the structural component of the thermal analysis requires attention to verify its effect on design performance.

A second safety basis analysis will also be performed to satisfy reactor safety requirements. Some acceptance criteria are required for off-normal and safety scenarios (i.e., no melting of experimental components and no boiling of reactor primary coolant. The analysis must demonstrate that site safety is not violated by the experiment under conditions.

Likewise, neutronic calculations will require an informed model or irradiation location boundary condition for successful performance of design and safety basis analyses.

\subsubsection{Quality Assurance and Inspection}

A quality assurance plan (QAP) must be established, maintained, and executed in accordance with the applicable criteria of the user facility's quality assurance program. The QAP is an enabling document for quality-related work associated with NTP IP activities, and it is to be implemented by any primary fabrication and assembly organization or any subcontracted organizations.

For example, the Oak Ridge National Laboratory (ORNL) Quality Assurance Program complies with these requirements by addressing the requirements contained in US Department of Energy (DOE) Order 414.1D and in 10 Code of Federal Regulations (CFR) 830, Subpart A. The program is applied on a graded basis to all work activities at the laboratory. ORNL's Quality Assurance Program also provides the flexibility and authorization to develop activity-specific programs to meet national and international 
quality standards, along with sponsor needs. Furthermore, as applicable to nuclear components, ORNL handles such pertinent activities to be conducted under the quality assurance rigor specified in ASME NQA-1-2008, with the NQA-1a-2009 Addendum, "Quality Assurance Requirements for Nuclear Facility Applications" (NQA-1-2008) standard, and in the NRC-mandated 10CFR50, Appendix B, "Quality Assurance Criteria for Nuclear Power Plants and Fuel Reprocessing Plants."

The QAP for this effort will dictate the appropriate protocols for handling material and part inspection, which includes material traceability, dimensional inspection, cleaning assembly, and welding. This document will also dictate the format of the quality assurance fabrication package that accompanies an IP experiment, as well as any deviation requests and nonconformance reporting.

\subsection{POST-IRRADIATION EXAMINATION}

PIE is the key to qualifying the fuel test articles. The PIE process will generally consist of material testing and fission gas release analysis. These data will quantify material properties as a function of burn-up, thermal cycling, fission density, etc., and they will also aid in fuel optimization and down-selection. Surrogate and fuel specimens used in the IP testing phase will be primarily subjected to microstructure examination and characterization by scanning electron microscopy and transmission electron microscopy techniques. Other material testing will be conducted as necessary and as the need arises. This testing may include investigating fracture toughness, tensile strength, thermal diffusivity. This work will continue in parallel with IP testing phase. 


\section{PHASE 3: PROTOTYPIC FUEL TESTING}

Prototypic fuel testing is the final irradiation testing phase for this effort. Prototypic fuel testing assumes that fuel parameters are optimized and fabrication processes of record are in place. The prototypic geometry tests must demonstrate scalability of full-length elements by establishing predictable performance that is comparable to observed subscale element behavior under the same operating conditions [5]. The scale of this testing should begin with single fuel element assemblies and then subsequently scale up to multiple assemblies in one experiment. These experiments should be instrumented to the extent that the experimental conditions allow while potentially controlling the hydrogen atmosphere within the experiment. These IP prototypic experiments should investigate normal, safety qualification, and limiting condition scenarios. Data produced from these experiments will be used to design a specification for subsequent full-scale testing and licensure of the reactor. Given the potentially wide range of tests and fuel configurations, multiple user facilities may be required. A tailored version of a PIE test plan will be created to perform prototypic fuel specimen characterization at all facilities proposed for IP experiment(s). This will verify that the equipment, instruments, and infrastructure are in place to support the qualification effort.

\subsection{QUALIFICATION OF A PROTOTYPIC FUEL EXPERIMENT}

Even though this testing involves more complex geometries and a longer list of design requirements, qualification of a prototypic fuel experiment mirrors the process described for IP testing. A design and safety basis must be established through engineering drawings, properly documented analysis calculations, and an approved QAP that details protocols for handling material acquisitions, fabrication, inspection, and experiment assembly. As described above, these qualification documents must be specific to the reactor or user facility, and interaction with each facility's staff members is imperative. Furthermore, lessons learned from the earlier IP efforts should be incorporated into the design and qualification of the prototypic fuel irradiation experiment development.

\subsection{SHIPPING OF PROTOTYPIC FUELS EXPERIMENTS}

Transportation and shipping protocols, mentioned briefly above, will be based on the limited amount of radioactive material used in the OOP and IP experiments. Given the number of cooperative entities involved with qualifying NTP fuel formats, it is likely that relatively large quantities of nuclear fuel will be transported by means of a method regulated by the Department of Transportation. Transportation safety documents (TSDs), shipping casks, and other packaging resources will be identified as part of the experiment qualification package. A TSD will prepared to meet the requirements in the DOE Order 460.1 C, Packaging and Transportation Safety, a safe harbor for a transportation documented safety analysis that must meet 10CFR830 requirements. 


\section{EXAMPLE OOP ENCLOSURE DESIGN CONSIDERATIONS}

A preliminary experimental design is proposed in this document to demonstrate the concept. The enclosure must be hermetically sealed and able to withstand sustained high-vacuum conditions. Because the equipment will ultimately be exposed to high-level radiation fields, use of polymer-based components (e.g. O-rings) is highly discouraged. Furthermore, the internal contents of the container should be easily accessible so that the samples may be retrieved for post-heat testing and PIE at later stages. ConFlat ${ }^{\circledR}$ (CF) flanges, which use copper gaskets and have a knife-edge design to achieve and maintain extreme vacuum seals, are readily available off-the-shelf products for sealing any penetration in a high vacuum experiment containment. These flanges are vacuum-tight and pressure resistant, and they can be modified to contain power pass-through connection, tubing fittings, and optical windows. This interface flexibility is required to instrument and power the OOP experiment and to collect the benchmark data.

The selection of external containment material must take weldability, thermophysical properties, and radiation tolerance and activation into account. Potential alloys include aluminum-6061, 300 series stainless steel, and grade- 5 titanium. A comparison of these alloys can be seen in

Table 5-1. The evaluations provided in the categories below are based on relative comparison of each of the parameters with respect to each metal's specific performance. Specifically, welding with aluminum alloys can be extremely challenging due to the formation of porosity in the weld joint resulting from surface contaminations (i.e., $\mathrm{Al}_{2} \mathrm{O}_{3}$, hydrocarbons, and contaminated shield gas). This can also be caused by dissolution of hydrogen gas from the weld metal during solidification [9]. On the other hand, stainless steel alloys and titanium alloys generally have good weldability when they are welded under a tightly controlled atmosphere [10] [11]. While thermophysical structural properties are considered to ensure that the container maintains integrity while in operation, the most sensitive parameter is the thermal conductivity. This parameter is crucial because of its heat transfer implications at the boundary (i.e., heat sink). Aluminum alloys have very high values of thermal conductivity, while stainless steel alloy and titanium alloy have roughly an order of magnitude less conductivity than that of aluminum [12]. In light of this comparison and the fact that stainless steel and titanium still have moderately good thermal conductivity, aluminum is given a favorable ranking, while the remaining two candidates are given a neutral ranking. The final parameter quantifies radiation tolerance and activation. While all materials have reasonably good resistance to irradiation damage (i.e., swelling and embrittlement), stainless steel becomes highly activated with isotopes such as ${ }^{59} \mathrm{Fe}$ and ${ }^{60} \mathrm{Co}$. These two isotopes have decay schemes that produce high-energy gamma rays, causing the material to be more difficult to ship, handle, and dispose of. Based on this ranking system, the grade 5 titanium is the recommended choice for IP and OOP enclosure material.

It should be noted that grade- 5 titanium CF fitting can be rather expensive. For prototyping and testing in the OOP container, it is possible to exchange the container and fitting material for stainless steel, as the activation concerns for the less expensive stainless materials are not an issue during OOP testing. Another option is to fabricate the container from a titanium-to-stainless bimetallic inertia weld joint. This option allows for a titanium enclosure using off-the-shelf- stainless steel fittings.

Table 5-1. Comparison of containment materials

\begin{tabular}{lcccc}
\hline \multicolumn{1}{c}{ Material } & Weldability & $\begin{array}{c}\text { Thermophysical } \\
\text { properties }\end{array}$ & $\begin{array}{c}\text { Radiation tolerance } \\
\text { and activation }\end{array}$ & Rank \\
\hline Aluminum-6061 & -1 & 1 & 1 & 1 \\
300 series stainless steel & 1 & 0 & -1 & 0 \\
Grade 5 titanium & 1 & 0 & 1 & 2 \\
\hline
\end{tabular}


The OOP enclosure shall be fitted with pass-throughs and penetrations to provide the necessary connections with the experiment for proper atmosphere control and instrumentation to gather performance data during heating. As stated earlier, the enclosure can be designed to use specialized CF fittings to provide these penetrations and interfaces. The required resources that would utilize these penetrations include but are not limited:

- Alternate or direct current power service inside the enclosure to directly heat the sample

- Thermocouple instrumentation to test lower (and potentially higher) temperature operating regimes

- Gas lines to impart various atmospheric conditions (vacuum, partial vacuum with inert gas, etc.)

- An aperture window for observing the experiment with optical measurement equipment, along with video and photographic documentation.

The containment enclosure must be sufficiently insulated so that the specimen can be driven to temperatures greater than $2,500 \mathrm{~K}$. Insulation requirements include:

- Good stability at high temperature

- Reasonable compliance and thickness

- Well characterized thermal conductivity at high temperatures

- Usability in vacuum and inert atmospheres

- Compatibility with nuclear radiation fields

A strong candidate material insulator is the SIGRATHERM GFA soft graphite felt, produced by SGL Group. This material is in the form of a pliant, soft felt. It is manufactured in thicknesses between 3-11.5 $\mathrm{mm}$. SIGRATHERM has extremely low thermal conductivity $\left(\sim 0.13 \mathrm{~W} / \mathrm{m}-\mathrm{K}\right.$ at $\left.1,000{ }^{\circ} \mathrm{C}\right)$, and it has a usable range up to $2,475 \mathrm{~K}$ [13]. It can be used in vacuum and inert atmospheres, with comparable thermal conductivity performance over a wide temperature range, as shown in Figure 5-1. Graphite has a long history of application in nuclear environments and is predominantly known for its neutron moderation properties. Graphite tends to swell under irradiation due to neutron damage, leading to a sizeable amount of stored energy in the material. The stored energy can spontaneously release (known as the Wigner effect) at a threshold irradiation temperature of roughly $200{ }^{\circ} \mathrm{C}$ [14]. Since the density of the felt is roughly $4 \%$ of the density of solid graphite, any negative impacts on thermal performance of the insulator (and enclosure) due to graphite swelling and release of Wigner energy are minimal [12] [13].

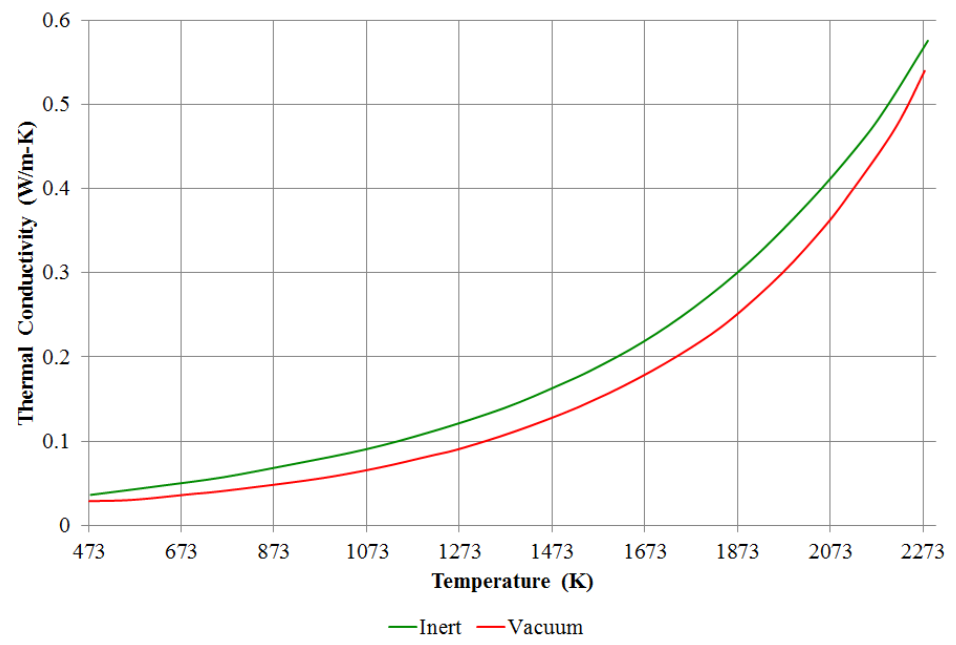

Figure 5-1. SIGRATHERM GFA thermal conductivity as a function of temperature (reproduced from SGL Group data [13]. 


\section{SUMMARY AND CONCLUSIONS}

This TIP for irradiation testing and qualification for NTP fuels outlines the necessary steps to meet the requirements for an irradiation qualification plan found in Benensky and Qualls [5]. Potential user facilities that provide a wide range of capabilities, services, and expertise can be found on the Nuclear Science User Facility website (https://nsuf.inl.gov/). Also, three serial functions are discussed to achieve fuel qualification: OOP testing, IP testing, and prototypic fuel testing. The primary effort for completing these key tasks entails developing complex designs to (1) encapsulate geometries of surrogate and fuels specimens, (2) gather material and performance data, and (3) support fuel optimization and qualification. Table 6-1 provides a complete list of properties and parameters of interest [5].

Table 6-1. Properties and parameters of interest to support NTP fuel qualification

\begin{tabular}{|c|c|c|}
\hline \multicolumn{3}{|c|}{ Material properties } \\
\hline $\begin{array}{l}\text { - Melting point (and range) } \\
\text { - Coefficient of thermal } \\
\text { expansion } \\
\text { - Yield strength } \\
\text { - Ultimate strength }\end{array}$ & $\begin{array}{l}\text { - Elastic modulus } \\
\text { - Poisson's ratio grain size } \\
\text { - Grain growth rates } \\
\text { - Specific heat capacity } \\
\text { - Thermal conductivity }\end{array}$ & $\begin{array}{l}\text { - Surface emissivity } \\
\text { - Vapor pressures } \\
\text { - Creep properties } \\
\text { - Critical stress intensities } \\
\text { - Fatigue properties } \\
\end{array}$ \\
\hline \multicolumn{3}{|c|}{ Nuclear Properties } \\
\hline $\begin{array}{l}\text { - Burnup rate } \\
\text { - Fission product buildup by } \\
\text { species }\end{array}$ & $\begin{array}{l}\text { - Fuel microcracking } \\
\text { dependence on burnup and } \\
\text { irradiation temperature }\end{array}$ & $\begin{array}{l}\text { - Fission product decay rate } \\
\text { - Embrittlement regime }\end{array}$ \\
\hline \multicolumn{3}{|c|}{ Performance Parameters } \\
\hline $\begin{array}{l}\text { - Maximum operating } \\
\text { temperature } \\
\end{array}$ & - Maximum operating lifetime & $\begin{array}{l}\text { - Operating lifetime at } \\
\text { temperature }\end{array}$ \\
\hline \multicolumn{3}{|c|}{ Compatibility } \\
\hline $\begin{array}{l}\text { - } \text { Microstructure and } \\
\text { restructuring }\end{array}$ & $\begin{array}{l}\text { - Hydrogen compatibility (and } \\
\text { reaction rates) } \\
\text { - Fission product retention } \\
\text { capability }\end{array}$ & $\begin{array}{l}\text { - Fission products released } \\
\text { - Fission product swelling } \\
\text { - }\end{array}$ \\
\hline
\end{tabular}

A preliminary example of an irradiation test matrix is provided in Table 6-2.

Table 6-2. Example irradiation test matrix

\begin{tabular}{lcccccc}
\hline \multicolumn{1}{c}{ Specimen format } & \multirow{2}{*}{ OOP } & \multirow{2}{*}{ IP } & Prototypic & \multicolumn{3}{c}{ PIE } \\
\cline { 5 - 7 } & & & TEM $^{a}$ & Tensile & CTE $^{b}$ \\
\hline Phase I (graphite) specimen & $\checkmark$ & $\checkmark$ & & $\checkmark$ & & $\checkmark$ \\
Phase II surrogate specimen & $\checkmark$ & $\checkmark$ & $\checkmark$ & $\checkmark$ & $\checkmark$ & $\checkmark$ \\
Phase III fueled specimen & & $\checkmark$ & $\checkmark$ & $\checkmark$ & $\checkmark$ & $\checkmark$ \\
Phase IV prototypic fueled specimen & & $\checkmark$ & $\checkmark$ & $\checkmark$ & $\checkmark$ & $\checkmark$ \\
\hline $\begin{array}{l}{ }^{a} \text { TEM }=\text { transmission electron microscopy } \\
{ }^{b} \text { CTE }=\text { coefficients of thermal expansion }\end{array}$ & & & &
\end{tabular}

To gather the data for these tests, mechanical testing and PIE must be implemented in parallel to process the OOP, IP, and prototypic fuel samples. This document describes methodologies to successfully deploy these characterization efforts. Approaches to address other challenges, such as requirements for shipping and analysis specific to a user facility, are also outlined. This TIP should remain flexible due to the immature nature of the fuel. Over time, as progress is made and information gathered, better insights will be provided on how to approach certain aspects of this process. The document should be reviewed 
periodically, especially during transition periods between major tasks, to verify its relevance and to update the approach as needed.

\subsection{PRELIMINARY TIP SCHEDULE}

A general task and deliverables schedule will provide a starting point for this work. A Gantt chart presenting the proposed schedule can be seen in Figure 6-1. Note that the schedule is based on best estimate effort and completion times of similar programs, with average contingency and resource availability. However, the schedule can be accelerated if adequate priority and funding are designated for this program.

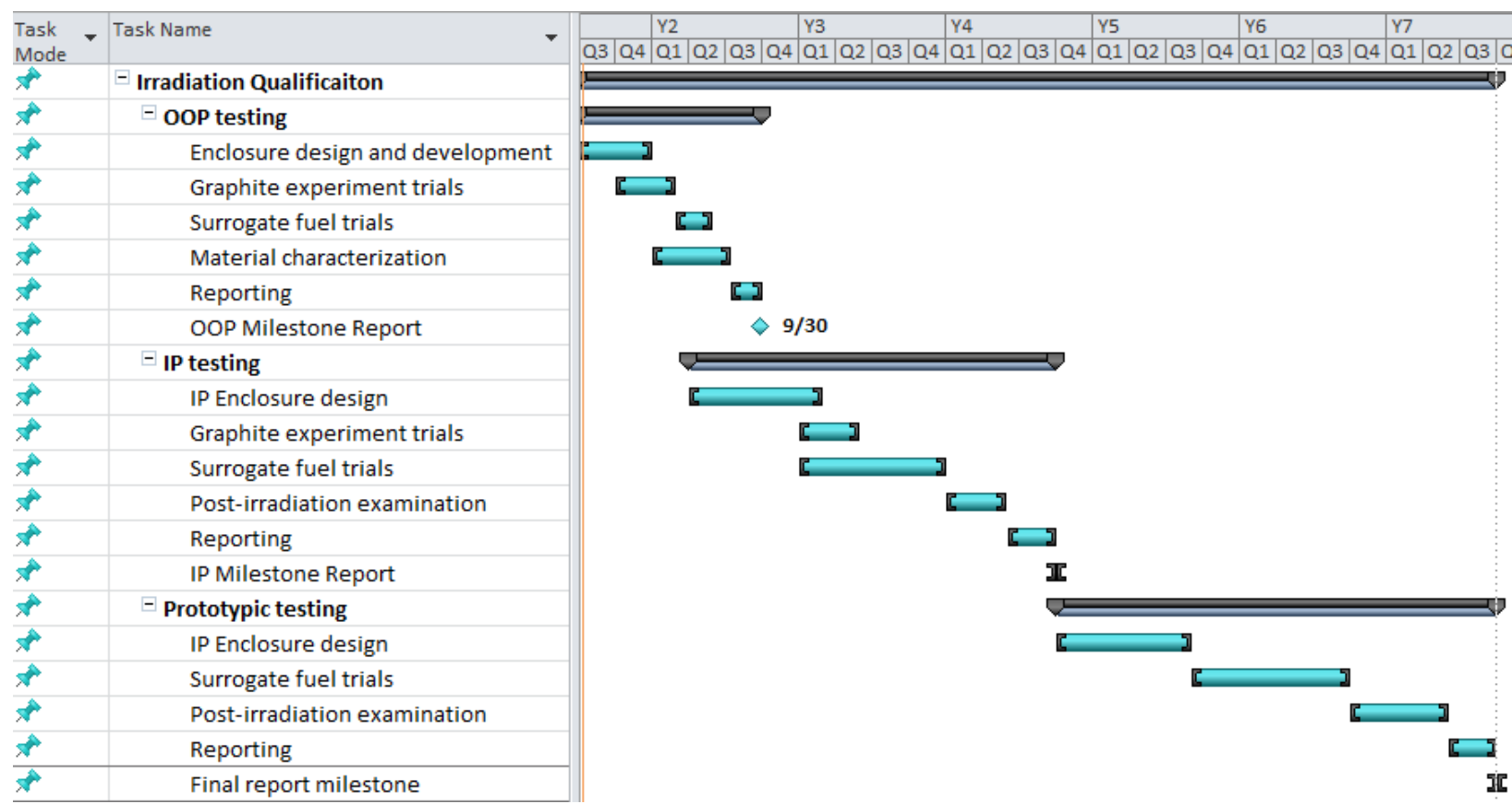

Figure 6-1. TIP sequence of tasks. 


\section{FUEL QUALIFICATION FACILITIES}

Quaification of NTP fuel will require the use of several material test facilites, as well as radiological and PIE facilities in the United States. Research reactors and hot cell facilities will also be integral in qualifying the NTP fuel system. Several research reactors are available at DOE and university sites. These sites have their own strengths and weaknesses for experimentation and testing (instrumentability, nuetron flux spectra, range of irradiation experiment varieties, etc.). Based on the specific NTP fuel form, one or more sites will be selected to perform this work. Likewise, multiple hot cell facilties are available to perform PIE and characterization, each of which has its own strengths and weaknesses. 


\section{REFERENCES}

[1] S. K. Borowski, D. R. McCurdy and T. W. Packard, "Nuclear thermal rocket (NTR) propulsion: A proven game-changing technology for future human exploration missions," in GLEX2012.09.4.6x12341, Washington, DC, 2012.

[2] A. Kronenberg and F. A. Cucinotta, "Space Radiation Protection Issues," Health Physics, vol. 103, no. 5, pp. 556-567, 2012.

[3] J. M. Napier, "NERVA Fuel Element Development Program Summary Report - July 1966 through June 1972, Extrusion Studies," Oak Ridge Y-12 Plant, Y-1852, Oak Ridge, Tennessee 37830, 1973.

[4] National Space Policy of the United States, 28 June 2010. [Online]. Available: https://www.nasa.gov/sites/default/files/national_space_policy_6-28-10.pdf. [Accessed 15 August 2017].

[5] K. M. Benensky and A. L. Qualls, "A Preliminary Nuclear Thermal Propulsion Fuel Qualification Plan," Oak Ridge National Laboratory, ORNL/LTR-2017/119, Oak Ridge, TN, 2017.

[6] K. Jousten, Handbook of Vacuum Technology, Weinheim, DE: Wiley-VCH, 2008.

[7] W. Kirk, "Nuclear Furnace-1 Test Report," Los Alamos Scientific Laboratory, LA-5189-MS, 1973.

[8] D. Pelaccio, "Nuclear Thermal Propulsion Carbide Fuel Corrosion and Key Issues," The National Aeronautics and Space Administration, NASA-CR-197533, 1994.

[9] G. Mathers, Welding of Aluminium and Its Alloys, Cambridge Woodhead Publishing Limited, 2002.

[10] P. Korinko and S. Malene, "Considerations for the weldability of types 304L and 316L stainless steel," Practical Failure Analysis, vol. 1, no. 4, 2001.

[11] S. Lampman, Weld integrity and performance: a source book adapted from ASM International handbooks, conference proccedings, and technical books, Materials Park, Ohio : ASM International, 1997.

[12] D. R. Lide, CRC Handbook of Chemistry and Physics, 86 Edition, 2005.

[13] SGL Group, "Soft Felt for High Temperature Furnaces," [Online]. Available: https://www.sglgroup.com/cms/international/products/product-groups/cfrc_felt/speciality-graphitesfor-high-temperature-furnaces/soft-felt.html. [Accessed July 2017].

[14] N. C. Gallego and T. D. Burchell, "A Review of Stored Energy Release of Irradiated Graphite," Oak Ridge National Laboratory, ORNL/TM-2001/378, Oak Ridge, TN, 2011.

[15] L.L Snead et. al., "Technology Implementation Plan: Fully Ceramic Microencapsulated Fuel for Commercial Light Water Reactor Application," Oak Ridge National Laboratory, Oak Ridge, TN, 2015.

[16] J.D. Bess et. al., "Neutron Radiography (NRAD) Reactor 64-Element Core Upgrade," Idaho National Laboratory, Idaho Falls, ID, 2014. 